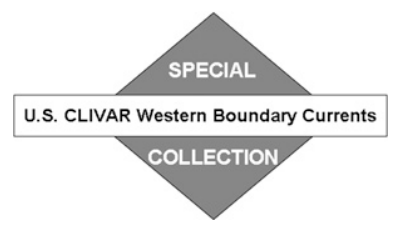

\title{
Numerical Investigations of Seasonal and Interannual Variability of North Pacific Subtropical Mode Water and Its Implications for Pacific Climate Variability
}

\author{
XUJing JiA DAVIS \\ Physical Oceanography Department, Woods Hole Oceanographic Institution, Woods Hole, Massachusetts \\ LEWIS M. ROTHSTEIN \\ Graduate School of Oceanography, University of Rhode Island, Narragansett, Rhode Island \\ WILLIAM K. DEWAR \\ Department of Oceanography, The Florida State University, Tallahassee, Florida \\ DIMITRIS MENEMENLIS \\ Jet Propulsion Laboratory, California Institute of Technology, Pasadena, California
}

(Manuscript received 16 September 2009, in final form 23 August 2010)

\begin{abstract}
North Pacific Subtropical Mode Water (NPSTMW) is an essential feature of the North Pacific subtropical gyre imparting significant influence on regional SST evolution on seasonal and longer time scales and, as such, is an important component of basin-scale North Pacific climate variability. This study examines the seasonalto-interannual variability of NPSTMW, the physical processes responsible for this variability, and the connections between NPSTMW and basin-scale climate signals using an eddy-permitting 1979-2006 ocean simulation made available by the Estimating the Circulation and Climate of the Ocean, Phase II (ECCO2). The monthly mean seasonal cycle of NPSTMW in the simulation exhibits three distinct phases: (i) formation during November-March, (ii) isolation during March-June, and (iii) dissipation during June-Novembereach corresponding to significant changes in upper-ocean structure. An interannual signal is also evident in NPSTMW volume and other characteristic properties with volume minima occurring in 1979, 1988, and 1999. This volume variability is correlated with the Pacific decadal oscillation (PDO) with zero time lag. Further analyses demonstrate the connection of NPSTMW to the basin-scale ocean circulation. With this, modulations of upper-ocean structure driven by the varying strength and position of the westerlies as well as the regional airsea heat flux pattern are seen to contribute to the variability of NPSTMW volume on interannual time scales.
\end{abstract}

\section{Introduction}

Mode waters are waters with exceptionally uniform properties over an extended depth range. Regions of mode water formation are of particular interest to climate since these are areas where atmospheric variability is transmitted to large volumes of water that penetrate and are sequestered below the surface layer. Mode waters integrate the atmosphere's influence on the ocean

Corresponding author address: Xujing Jia Davis, Physical Oceanography Dept., Woods Hole Oceanographic Institution, Clark 344b, MS\#21, Woods Hole, MA 02543.

E-mail:xdavis@whoi.edu and therefore provide a link between the shorter time scales of the atmosphere and the longer time scales of the oceanic subsurface layers (Latif and Barnett 1994).

North Pacific Subtropical Mode Water (NPSTMW) is one such mode water. NPSTMW typically forms in the northwestern corner of the subtropical gyre, to the east of the Kuroshio and south of the Kuroshio Extension (KE). The properties of NPSTMW have been extensively surveyed from observational studies (Masuzawa 1969; Suga and Hanawa 1990; Bingham 1992; Taneda et al. 2000; Oka and Suga 2003; Uehara et al. 2003; Qiu and Chen 2006; Qiu et al. 2006, 2007) with emphasis on seasonal time scales, as summarized by Oka (2009). More recently, Hanawa and Kamada (2001), Roemmich 
et al. (2005), and Qiu and Chen (2006) employed longer data records from the World Ocean Database, XBT surveys, satellite altimeters, and Argo profiling floats to provide the first evidence of interannual and decadal variations in NPSTMW.

There have also been several numerical investigations of NPSTMW variability based on general circulation models (GCMs) (Xie et al. 2000; Yasuda and Kitamura 2003; Hosoda et al. 2004; Taguchi et al. 2005; Rainville et al. 2007; Yamanaka et al. 2008). While the interannual variability of NPSTMW core-layer temperature (CLT; Hanawa and Kamada 2001; Yasuda and Kitamura 2003) and formation region (Deser et al. 1999; Schneider and Miller 2001; Yasuda and Kitamura 2003; Taguchi et al. 2005) have been studied in the context of climate variability, some important questions remain unresolved. These questions include the spatial distribution, the annual formation and destruction, and the interannual volume change of NPSTMW.

Using a 3-yr record from a high-resolution configuration of the Parallel Ocean Program (POP), Rainville et al. (2007) examined the seasonal and interannual variability of NPSTMW. The present study extends analysis of high-resolution model results to a longer period (1979-2006) and investigates the relation of interannual NPSTMW volume variability to the established Pacific climate signals to provide new insight on upper-ocean dynamics and on the role of NPSTMW in North Pacific climate variability. Specifically, model results are analyzed to investigate NPSTMW properties and the associated dynamics on seasonal-to-interannual time scales. To accomplish this, we first construct a definition of NPSTMW based on the model output and on previous observational and numerical investigations. With this definition we show that two distinct regimes of NPSTMW variability exist: seasonal and interannual. The seasonal cycle of model NPSTMW formation, isolation, and dissipation is described in detail. The interannual regime of model NPSTMW variability is shown to be closely tied to the phase change of the Pacific decadal oscillation (PDO) index. This connection is more clearly seen through an analysis of interannual changes in basinwide wind stress and surface heat flux.

\section{Model description}

This study is based on a global ocean simulation made available by the Estimating the Circulation and Climate of the Ocean, Phase II (ECCO2) project (Menemenlis et al. 2008). This particular ECCO2 simulation is labeled Cube76, and it was carried out using a global, eddypermitting configuration of the Massachusetts Institute of Technology general circulation model (MITgcm;
Marshall et al. 1997). A cube-sphere grid (Adcroft et al. 2004) is employed with horizontal grid spacing of approximately $18 \mathrm{~km}$. The model has 50 vertical levels to a maximum depth of $6135 \mathrm{~m}$. Level thicknesses range from $10 \mathrm{~m}$ in the top $100 \mathrm{~m}, 95 \mathrm{~m}$ at the $1000-\mathrm{m}$ depth, to a maximum of $450 \mathrm{~m}$ near the bottom. Surface heat flux and evaporation are calculated using the Large and Pond (1982) bulk formulae, and surface wind stress is calculated using the drag coefficient parameterization derived by E. Vera (1983, unpublished manuscript) (Large et al. 1995). Boundary layer and convective mixing in the ocean is parameterized according to Large et al. (1994). A more complete description of this model configuration is given in Menemenlis et al. (2005b) and in Fox-Kemper and Menemenlis (2008).

The ECCO2 simulation spans January 1979-November 2006. Its surface boundary conditions are obtained from the European Centre for Medium-Range Weather Forecasts (ECMWF) 40-year reanalysis (ERA-40; Uppala et al. 2005) except for precipitation, which is taken from the Global Precipitation Climatology Project (GPCP; Adler et al. 2003). The ECMWF analysis (Gibson et al. 1997) is used after August 2002 when the ERA-40 stops. This particular ECCO2 simulation was not directly constrained by oceanic data but several ocean model parameters used in this integration had previously been adjusted using a Green's function approach to reduce large-scale model data differences (Menemenlis et al. 2005a).

\section{Model NPSTMW property description}

\section{a. The definition of NPSTMW in ECCO2}

NPSTMW is typically observed in the upper $500 \mathrm{~m}$ of the water column with a temperature between $16^{\circ}$ and $19^{\circ} \mathrm{C}$ (Oka and Suga 2003) and with a salinity range of 34.65-34.8 (Suga and Hanawa 1990). It is readily identified by the aforementioned thermostads with potential density values of $24.8-25.7 \mathrm{~kg} \mathrm{~m}^{-3}$ (Masuzawa 1969; Suga and Hanawa 1990; Bingham 1992), lying just above and within the permanent thermocline in the western North Pacific subtropical gyre. NPSTMW is formed in late winter in the deep mixed layer immediately south of the Kuroshio and the KE, when the cold dry continental air (cold air outbreaks) encounters the warm waters advected northward from lower latitudes by the Kuroshio.

In a numerical investigation of North Pacific mode waters, Ladd and Thompson (2001) defined NPSTMW as a water mass primarily found in the region $15^{\circ}-50^{\circ} \mathrm{N}$, $135^{\circ} \mathrm{E}-180^{\circ}$, with low potential vorticity $(\mathrm{PV})(<2 \times$ $10^{-10} \mathrm{~m}^{-1} \mathrm{~s}^{-1}$ ) lying between densities of 25.125 and $25.625 \mathrm{~kg} \mathrm{~m}^{-3}$. More recent studies have applied similar criteria, specifying NPSTMW as water exhibiting the 


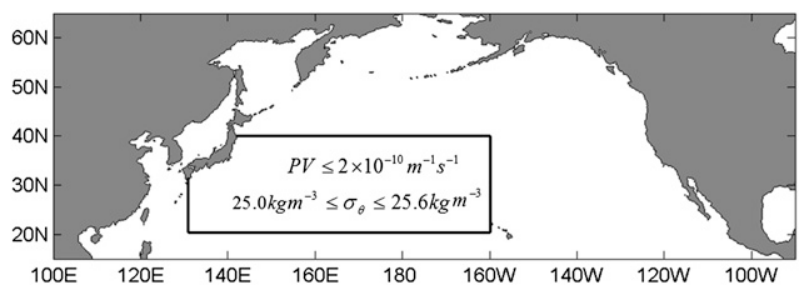

FIG. 1. The black rectangular region is the defined domain of NPSTMW. In the defined domain, water with PV $\leq 2 \times 10^{-10}$ $\mathrm{m}^{-1} \mathrm{~s}^{-1}$ and $25.0 \leq \sigma_{\theta} \leq 25.6 \mathrm{~kg} \mathrm{~m}^{-3}$ is the NPSTMW.

same PV minimum but with a potential density range of 25.0-25.5 $\mathrm{kg} \mathrm{m}^{-3}$ (Rainville et al. 2007) approximately in the region $25^{\circ}-42^{\circ} \mathrm{N}, 130^{\circ}-160^{\circ} \mathrm{E}$. In an observational investigation (Oka 2009), a smaller PV constraint $1.5 \times$ $10^{-10} \mathrm{~m}^{-1} \mathrm{~s}^{-1}$ is used and the NPSTMW is found to be confined between $16.0^{\circ}$ and $19.5^{\circ} \mathrm{C}$. Using this definition NPSTMW is located from the east of Japan to the date line (Oka 2009).

The definition of model NPSTMW used here is similar to the above and thus defined as water that satisfies the following: 1) PV less than or equal to $2 \times 10^{-10} \mathrm{~m}^{-1} \mathrm{~s}^{-1}$; 2) potential density between 25.0 and $25.6 \mathrm{~kg} \mathrm{~m}^{-3}$; and 3 ) water found within the region $20^{\circ} \mathrm{N}-40^{\circ} \mathrm{N}, 130^{\circ} \mathrm{E}-160^{\circ} \mathrm{W}$ and east of the islands of Japan (Fig. 1). PV is here defined as $\mathrm{PV}=-(f / \rho)\left(\partial \sigma_{\theta} / \partial z\right)$, where $f$ is the Coriolis parameter, $\rho$ is the water density, and $\sigma_{\theta}$ is the potential density.

\section{b. Comparison with observations}

Figure 2 compares the mean and standard deviation of simulated and observed sea surface height ( $\mathrm{SSH}$ ) during the 1992-2006 period. The altimeter data product was produced by Ssalto/Duacs and distributed by Aviso, with support from Centre National d'Études Spatiales (CNES) (http://www.aviso.oceanobs.com/duacs/). Based on the mean SSH comparison (Figs. 2a and 2b), the KE is slightly northward in the ECCO2 simulation than it is in the observations, probably due to the limited horizontal resolution and to other deficiencies in the ocean model and in the surface boundary conditions (Yasuda and Kitamura 2003). The standard deviation of the simulated sea surface height (Fig. 2c) is $18 \%$ smaller overall than the
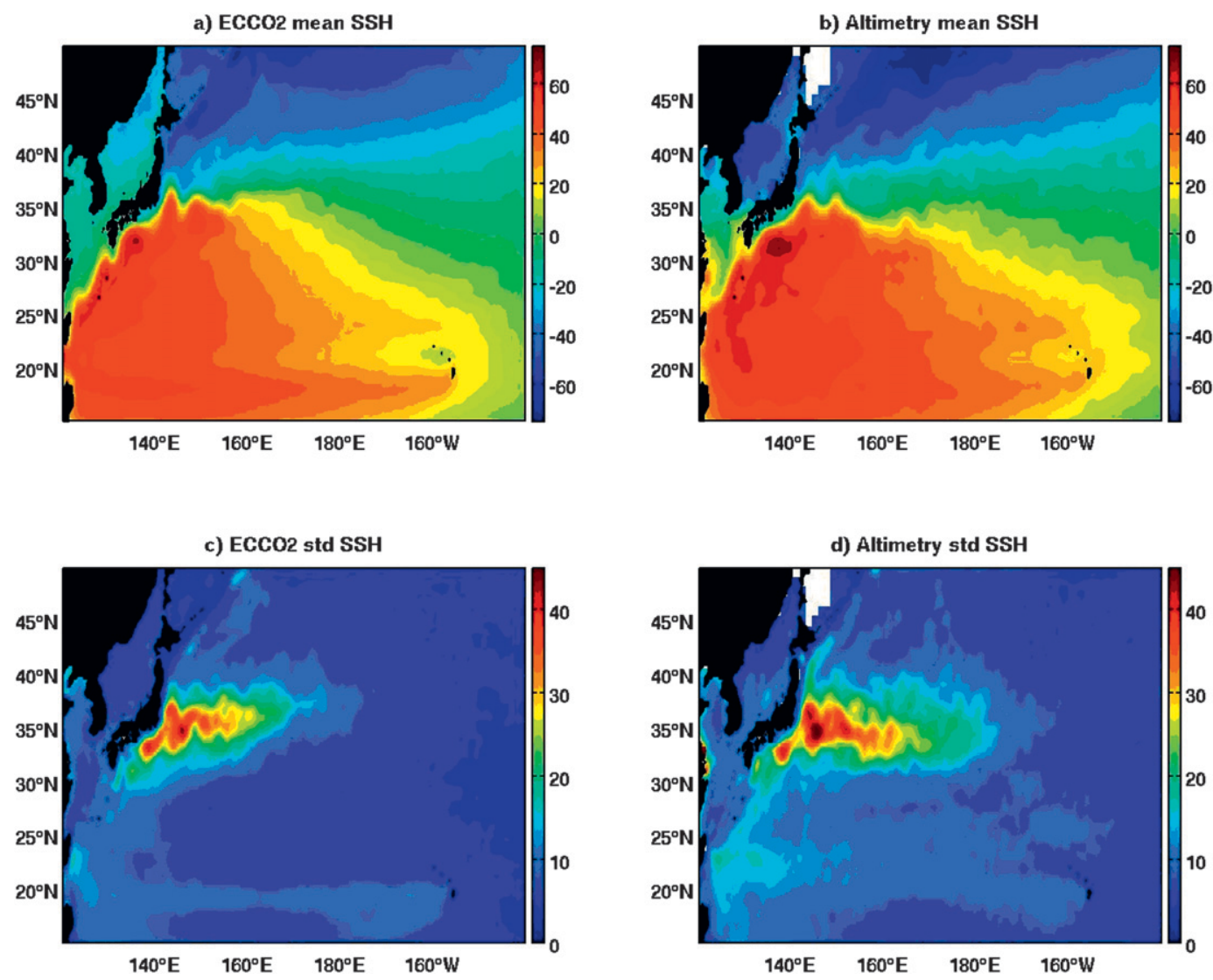

FIG. 2. The SSH anomaly $(\mathrm{cm})$ comparison between the ECCO2 simulation and the altimeter data product produced by Ssalto/Duacs and distributed by Aviso: 1992-2006 mean SSH for (a) ECCO2 and (b) altimetry; 1992-2006 standard deviation SSH for (c) ECCO2 and (d) altimetry. 
(a)

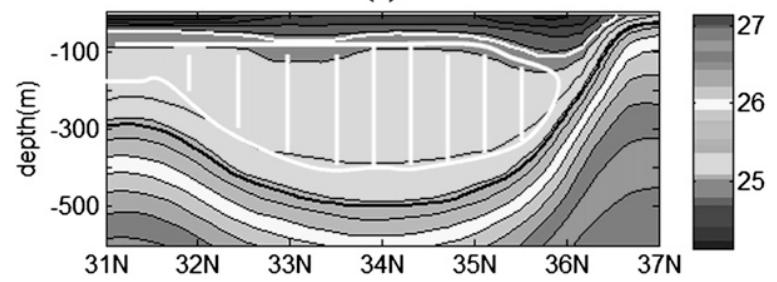

(b)

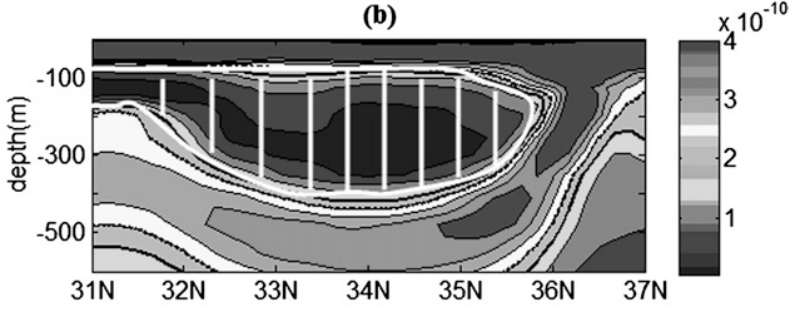

(c)

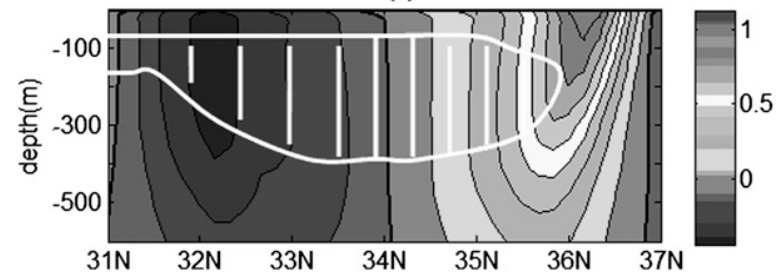

FIG. 3. Meridional cross section at $145^{\circ} \mathrm{E}$ of (a) potential density, (b) PV, and (c) zonal velocity $u$ in the ECCO2 simulation. The interval for the potential density, $\mathrm{PV}$, and zonal velocities are $0.2 \mathrm{~kg} \mathrm{~m}^{-3} \mathrm{~m}^{-3}, 0.5 \times 10^{-10} \mathrm{~m}^{-1} \mathrm{~s}^{-1}$, and $0.125 \mathrm{~m} \mathrm{~s}^{-1}$, respectively. The stippled areas are the defined NPSTMW in this study.

observations (Fig. 2d) and the maximum standard deviation is again shifted northward in the KE region relative to observations.

Notwithstanding the above model data differences, the NPSTMW is quite realistic compared with the observations. The stippled areas in Fig. 3 represent NPSTMW in ECCO2 simulation, as defined in the previous section. The simulated NPSTMW structure can be compared with the Kuroshio Extension System Study (KESS) observations (Figs. 2b, d, f in Rainville et al. 2007). In both model and observations for May
2004, NPSTMW appears as a thermostad lying below the surface layers and above $500 \mathrm{~m}$, with relatively homogenous temperature and PV structure surrounded by highly stratified temperature and by high PV waters. Cross sections of zonal velocity show that, both in ECCO2 simulation and in KESS observations, the large NPSTMW pool at $145^{\circ} \mathrm{E}$ resides just south of a strong eastward jet (KE) in layers of weaker westward velocity. At the time and location of comparison, however, a more northward position $(\sim 100 \mathrm{~km})$ of the KE and NPSTMW is found in the ECCO2 simulation than in the observations, consistent with the northward shift of the simulated KE relative to observations in Fig. 2.

\section{The seasonal variability of the model NPSTMW}

The spatial distribution and property averages over the volume of NPSTMW vary significantly from month to month. This variability manifests as changes in mode water properties, outcropping, spatial distribution, and net volume (Fig. 4). Indeed, distinct signatures of each of the seasonal stages of NPSTMW evolution (i.e., formation, isolation and dissipation) can be identified in both quantitative and qualitative terms. An analysis of the monthly mean seasonal cycle, calculated over the duration of the study period, is presented next. This analysis will later be used as a basis for studying NPSTMW variability on interannual time scales.

\section{a. The formation phase (November-March)}

The renewal or formation of new NPSTMW occurs primarily in boreal late fall and early winter (Fig. 5). Here, the $145^{\circ} \mathrm{E}$ cross section represents a typical section of the NPSTMW and is shown to demonstrate the seasonal variation. Beginning in November, deepening of the mixed layer becomes pronounced as a result of major atmospheric cooling with the onset of cold air outbreaks and the corresponding significant heat loss from the ocean to the atmosphere (Fig. 5k). Characteristically, newly formed NPSTMW initially appears north of and

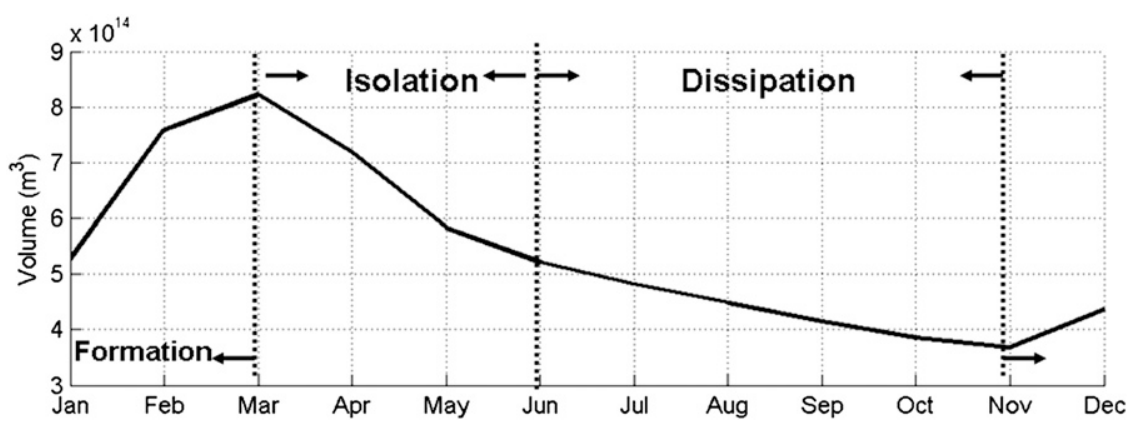

FIG. 4. The volume of NPSTMW in the mean seasonal cycle of the ECCO2 climatological fields. 

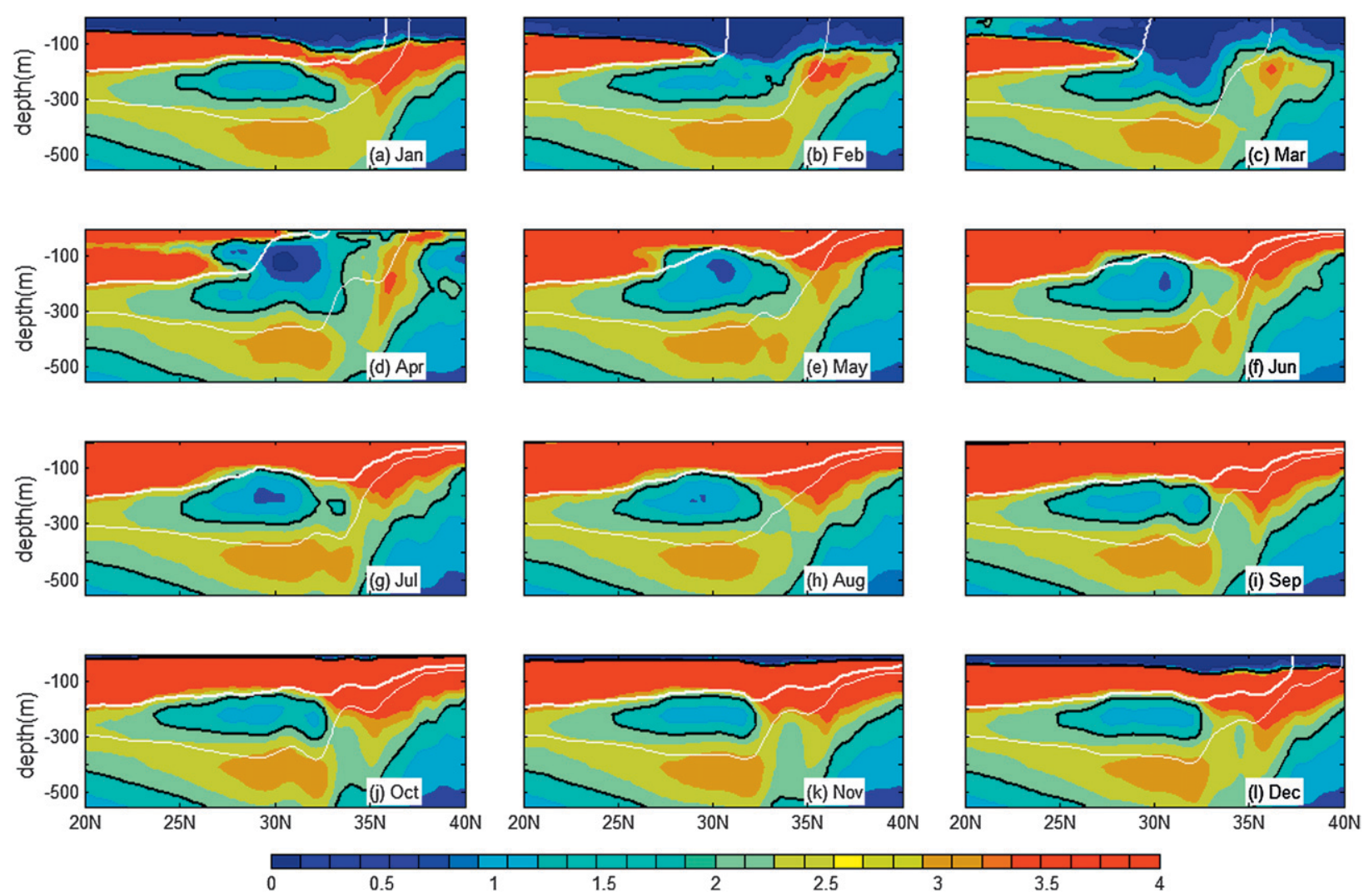

FIG. 5. Monthly meridional cross section at $145^{\circ} \mathrm{E}$ in the ECCO2 simulation. The color contours are PV with an interval of $0.5 \times$ $10^{-10} \mathrm{~m}^{-1} \mathrm{~s}^{-1}$. The black solid line represents $\mathrm{PV}=2.0 \times 10^{-10} \mathrm{~m}^{-1} \mathrm{~s}^{-1}$. The overlying thick and thin white lines are the 25.0 and $25.6 \mathrm{~kg} \mathrm{~m}^{-3}$ isopycnals, respectively. The water sandwiched between the two white lines and that has a PV smaller than the black solid line is the defined NPSTMW.

around the KE region, a known major formation region of NPSTMW (Ladd and Thompson 2001). This deepened mixed layer allows for the formation of a weakly stratified layer with low PV near the surface. In subsequent months, the outcrops migrate south and some initially formed NPSTMW north of and around KE becomes too cold to be NPSTMW. The newly formed NPSTMW within the outcrop region combines with other low PV water and penetrates deeper (Figs. 5a,b,c). In February and March, newly formed NPSTMW reaches sufficient depth to combine with NPSTMW remnants formed in the preceding year, and the net volume of NPSTMW reaches its maximum of $\sim 8.2 \times 10^{14} \mathrm{~m}^{3}$ (Figs. 4, 6c, 7c, and 8c).

During the early stages of formation, principally November-January, the spatial distribution of NPSTMW is mainly comprised of two regions: shallower, "newly formed" NPSTMW and a deeper remnant of previously formed NPSTMW from prior years (Figs. 7a,k,1 and $8 \mathrm{a}, \mathrm{k}, \mathrm{l})$. The new and previously formed NPSTMW have different characteristics. Newly formed NPSTMW begins to appear in November as a thin layer on the surface, exhibiting much lower PV ( $\sim 82 \%$ smaller $)$ (Fig. 6k). As more new NPSTMW forms, the discrepancy between the two types of NPSTMW becomes less noticeable. By February and March, a large amount of newly formed NPSTMW merges with old NPSTMW (Figs. 6b,c, 7b,c, and 8b,c) in the northern part and the remnant mode water can emerge at the surface through strong mixing, influencing wintertime SST. During the formation season, the newly formed NPSTMW is zonally banded from the east of Japan to west of $160^{\circ} \mathrm{W}$. This is in agreement both with a comprehensive observational study (Suga and Hanawa 1995) and with results using Argo profiling floats (Oka 2009), showing that NPSTMW is formed along the zonal band south of Kuroshio and KE (Oka 2009).

\section{b. The isolation phase (March-June)}

Wintertime mixing weakens from April and the outcropping of the 25.0 and 25.6 isopycnal surfaces at $145^{\circ} \mathrm{E}$ is visible south of $40^{\circ} \mathrm{N}$ in the $\mathrm{ECCO} 2$ simulation (Fig. 5c). In April and May, newly formed NPSTMW continues to subduct locally between the 25.0 and 25.6 

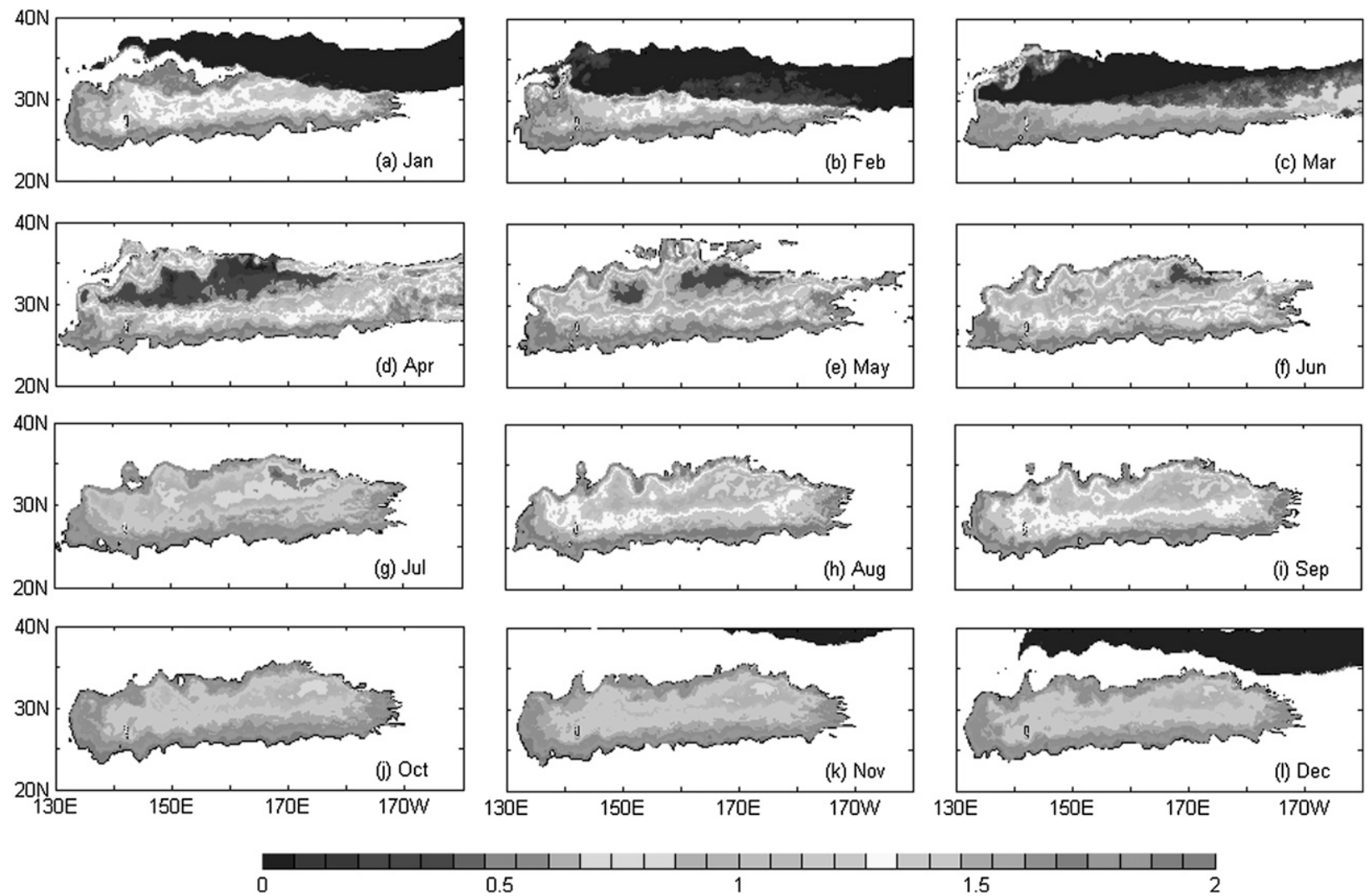

FIG. 6. The vertically averaged PV $\left(\times 10^{-10} \mathrm{~m}^{-1} \mathrm{~s}^{-1}\right)$ of NPSTMW for each month from the mean seasonal cycle of ECCO2 simulation.

isopycnals (Figs. 5d,e). The 25.0 and 25.6 isopycnal outcrop area becomes less prominent during these months in response to increased temperature in the atmosphere and upper ocean. By June, the outcrop area almost moves out of the defined NPSTMW region and NPSTMW becomes shielded from the surface, residing in a homogenous layer of temperature, salinity, and PV between the surface and $500 \mathrm{~m}$ (Fig. 5f). Throughout this isolation period, modifications of NPSTMW PV occur as the thermal structure changes in surrounding waters. Specifically, minimum PV becomes concentrated in the middle of the NPSTMW, surrounded by higher PV water (Figs. 6d,e,f). The latitudinal and longitudinal extent of NPSTMW decreases as the mode water mass evolves toward a more defined structure: a bowl with a thicker center and thinner edge (Fig. 8f), deeper in the southwest and shallower toward the northeast (Fig. 7f). The main feature of the isolation phase is the merging of the newly formed water and previously existing NPSTMW.

\section{c. The dissipation phase (June-November)}

Following the isolation phase, and prior to the onset of a new formation season, NPSTMW remains submerged beneath the surface, free of direct atmospheric contact (Figs. 5f-k). At the same time summer warming (JuneSeptember) and fall cooling (September-October) influence the seasonal thermocline structure and therefore the positions of the 25.0 and 25.6 isopycnals that bound the NPSTMW. NPSTMW shrinks both horizontally and vertically (Figs. 8f-j). The NPSTMW bowl gets thinner and thinner and the low PV signature in the center of the NPSTMW becomes less and less distinguished (Figs. 7f-j). By October, the lowest PV value is $45 \%$ bigger and the thickest part of the NPSTMW is $24 \%$ thinner than that in June. This NPSTMW bowl is also characterized by a distinct temperature structure, with the warmest to the west and the coolest to the east (not shown), which compare favorably with the NPSTMW structure observed by the Argo floats (Oka 2009).

\section{d. The annual formation/destruction of NPSTMW}

In the mean seasonal cycle of ECCO2 simulation, a significant volume gain/loss is apparent (Figs. 4, 5, and 8 ). The annual formation and destruction amount is equal in the mean seasonal cycle, which is $\sim 4.54 \times$ $10^{14} \mathrm{~m}^{3}$. Understanding the dynamics behind this volume change can yield information about the extent of 

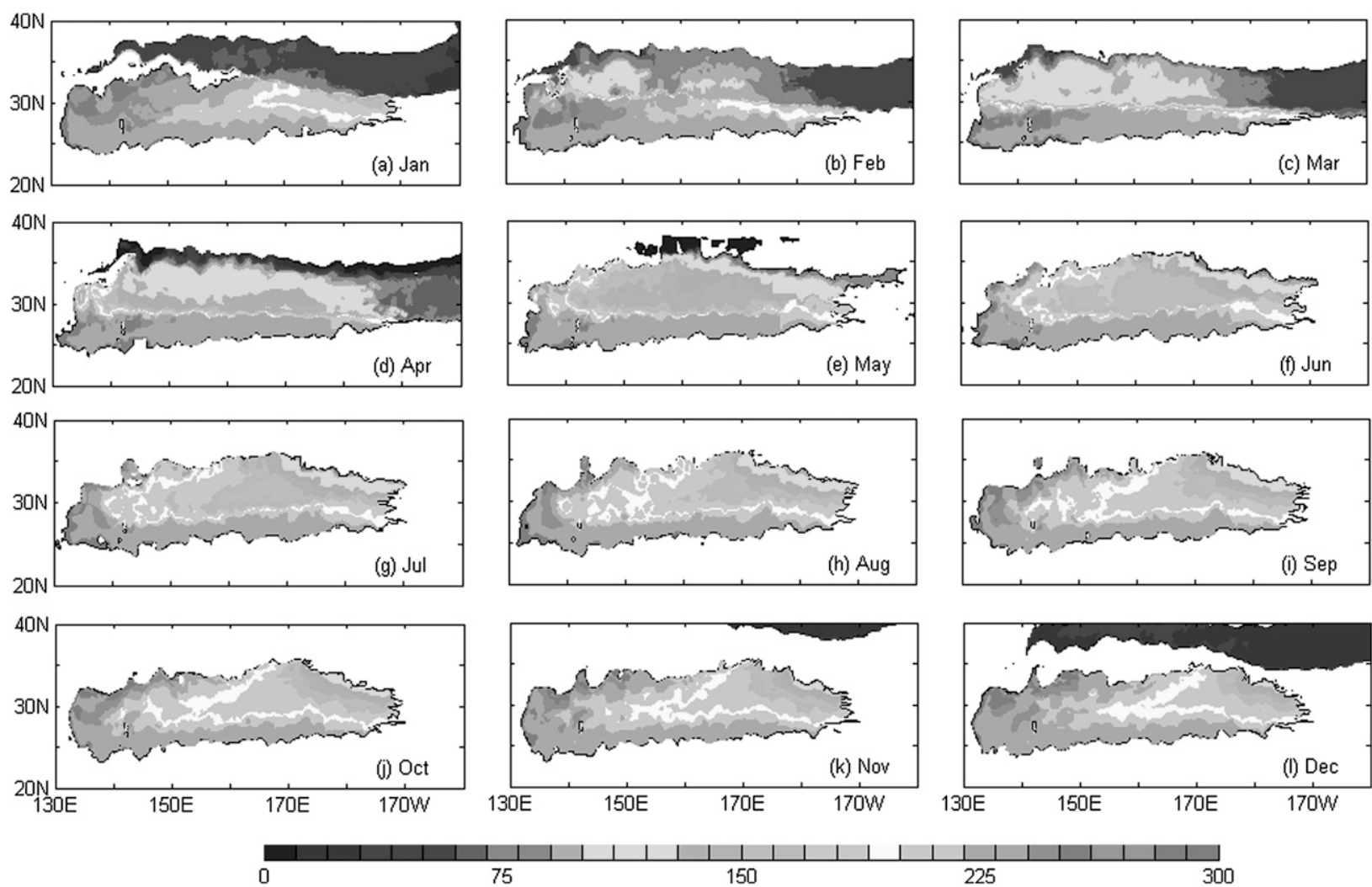

FIG. 7. As in Fig. 6, but for the vertically averaged depth $h(\mathrm{~m})$.

air-sea interaction during formation season, the reemergence of NPSTMW after its formation and hence help evaluate its feedback on the atmosphere. As discussed earlier, the volume gain happens during the formation season when the NPSTMW outcrops at the surface and intense air-sea heat exchange occurs. In the rest of this seasonal cycle, the volume loss persists through the isolation and dissipation periods. Three major mechanisms can account for the volume loss. The first is seasonal restratification; the switch from cooling to warming of the ocean surface in spring (March-May) destroys newly formed NPSTMW by breaking its low PV threshold. The second mechanism for NPSTMW loss is advection of mode water out of the defined NPSTMW region. This is apparent as an eastward flux during the isolation phase (Fig. 8d). The third mechanism is dissipation, both isopycnal and diapycnal. This mechanism may be dominant during the dissipation phase (Figs. $5 \mathrm{f}-\mathrm{k}, 6 \mathrm{f}-\mathrm{k}, 7 \mathrm{f}-\mathrm{k}$, and $8 \mathrm{f}-\mathrm{k}$ ). In numerical models, the diapycnal diffusion is often artificially exaggerated and, as a result, lateral and vertical processes can be of comparable magnitude. In the real ocean, eddies can transport heat and salt anomalies into the NPSTMW region and thereby alter the water masses. This can erode NPSTMW. The relative importance of the lateral and vertical diffusions in mode water destruction, though, is an open question and of interest to ongoing efforts.

\section{The interannual variability of the model NPSTMW}

We extend the above seasonal definitions to explore the interannual variability of various properties of NPSTMW.

\section{a. Volume, formation, and destruction}

Besides seasonality, year-to-year variability of the model NPSTMW is also evident (Figs. 9a,b). A quasidecadal oscillation is apparent with a volume minimum occurring toward the end of each decade $(1979,1988$, and 1999). The volume maximum is found in the early to mid part of the decades. The NPSTMW volume maximum and minimum values are found in years 1996 and 1999 , with values of $7.75 \times 10^{14} \mathrm{~m}^{3}$ and $4.19 \times 10^{14} \mathrm{~m}^{3}$, respectively. The volume change of NPSTMW in year $i$ $\left(\Delta V_{i}^{\mathrm{STMV}}\right)$ is mainly determined by the amount of newly formed NPSTMW ( $V_{i}^{\text {formation }}$ ) during the wintertime formation phase and the destruction $\left(V_{i}^{\text {destruction }}\right)$ during the isolation and the dissipation phases, that is, 

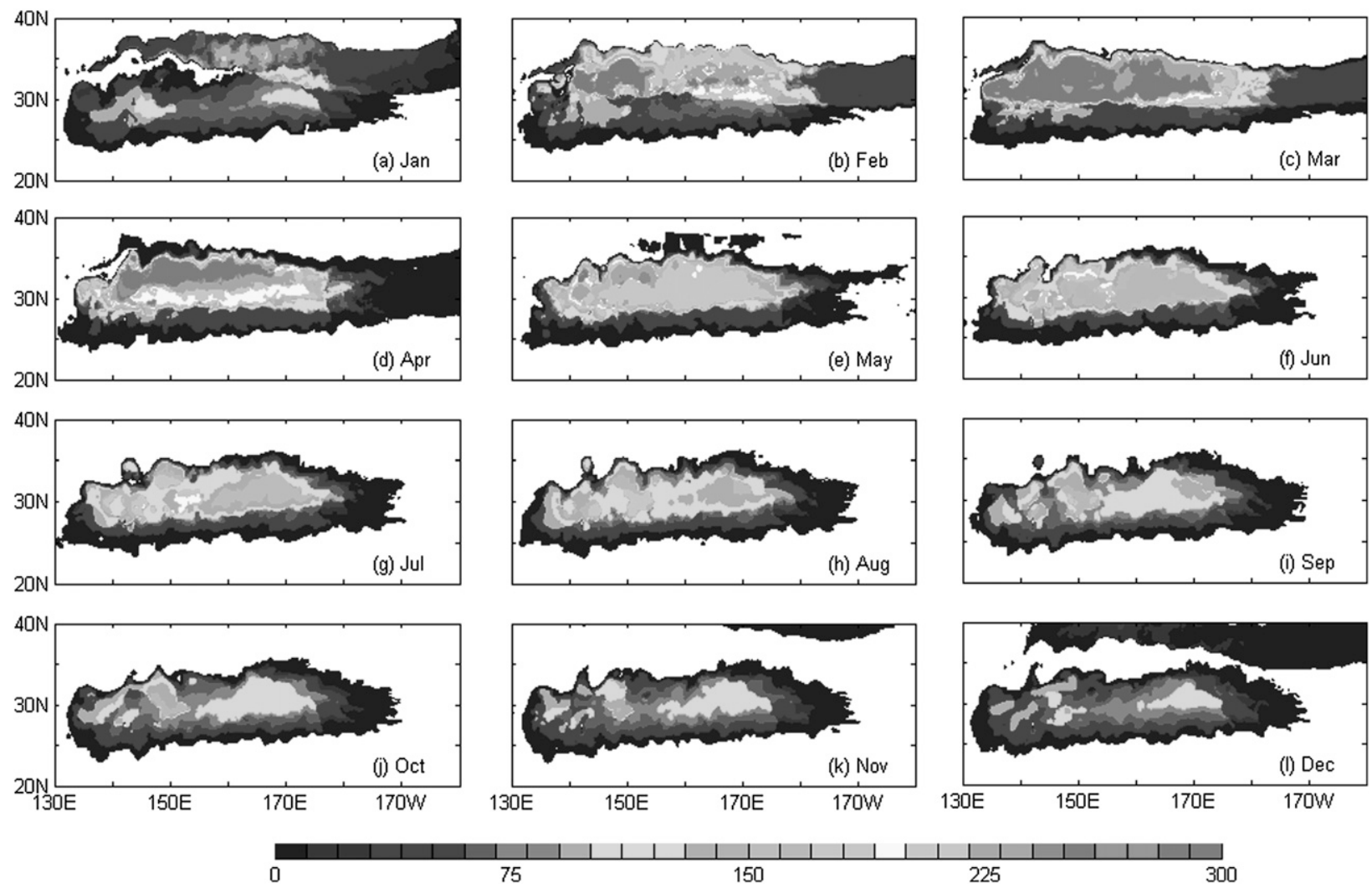

FIG. 8. As in Fig. 6, but for the vertically averaged thickness (m).

$$
\Delta V_{i}^{\mathrm{STMV}}=V_{i}^{\text {formation }}-V_{i}^{\text {destruction }}
$$

and the annual formation and destruction in year $i$ are

$$
V_{i}^{\text {formation }}=V_{i}^{\max }-V_{i-1}^{\min } ; \quad V_{i}^{\text {destruction }}=V_{i}^{\max }-V_{i}^{\min }
$$

where $V_{i}^{\max }$ is the volume maximum in year $i, V_{i}^{\min }$ and $V_{i-1}^{\min }$ are the volume minimums in year $i$ and $i-1$, respectively. Based on this definition, the annual NPSTMW formation and destruction does not show a clear correlation (Fig. 9c), but during a year when more/less NPSTMW is formed, more/less NPSTMW is destroyed. This relation is similar to that of the North Atlantic Eighteen Degree Water (EDW) (Kwon and Riser 2004). The volume change of NPSTMW $\Delta V_{i}^{\text {STMV }}$ (Fig. 9d) shows that near the end of the 80s and 90s, the annual NPSTMW destruction is more than the annual NPSTMW formation for several years continuously; the NPSTMW volume therefore decreases (Fig. 9d) and reaches its minimums in 1988 and 1999. The minimum (maximum) annual formation of NPSTMW occurs in 1999 (1991) with a value of $2.8 \times 10^{14}\left(6.1 \times 10^{14}\right) \mathrm{m}^{3}$, which gives an annual formation rate of $9(19) \mathrm{Sv}\left(1 \mathrm{~Sv}=10^{6} \mathrm{~m}^{3} \mathrm{~s}^{-1}\right)$. This value is on the same order as the annual formation rate $\sim 15 \mathrm{~Sv}$ (Speer and Tziperman 1990) and larger than the updated value $~ 3.5$ Sv (Kwon and Riser 2004) of North Atlantic EDW. Comparable to the annual formation rate, the minimum (maximum) annual destruction rate of NPSTMW in year 2000 (1995) is 11 (17) Sv. The turnover time of the NPSTMW, defined here by the ratio between the annual volume and formation (Kwon and Riser 2004), ranges from 1.0 to 2.0 years. This value is on the same order as that in previous studies of North Atlantic EDW (Worthington 1959; Jenkins 1982; Kwon and Riser 2004). Comparing years 1998-2000 with the results of Rainville et al. (2007), both the annual volume and formation rate in the ECCO2 simulation are about twice as much as that in the POP model. As a result, the turnover time in $\mathrm{ECCO} 2$ is similar to that in POP. The southward position in the POP simulation (Fig. 1 in Rainville et al. 2007) can reduce the amount of the NPSTMW formation and account for the volume difference between our result and that in the POP simulation. The defined NPSTMW region here is further east compared to that in Rainville et al. (2007); this area difference can be another factor to explain the volume difference. 

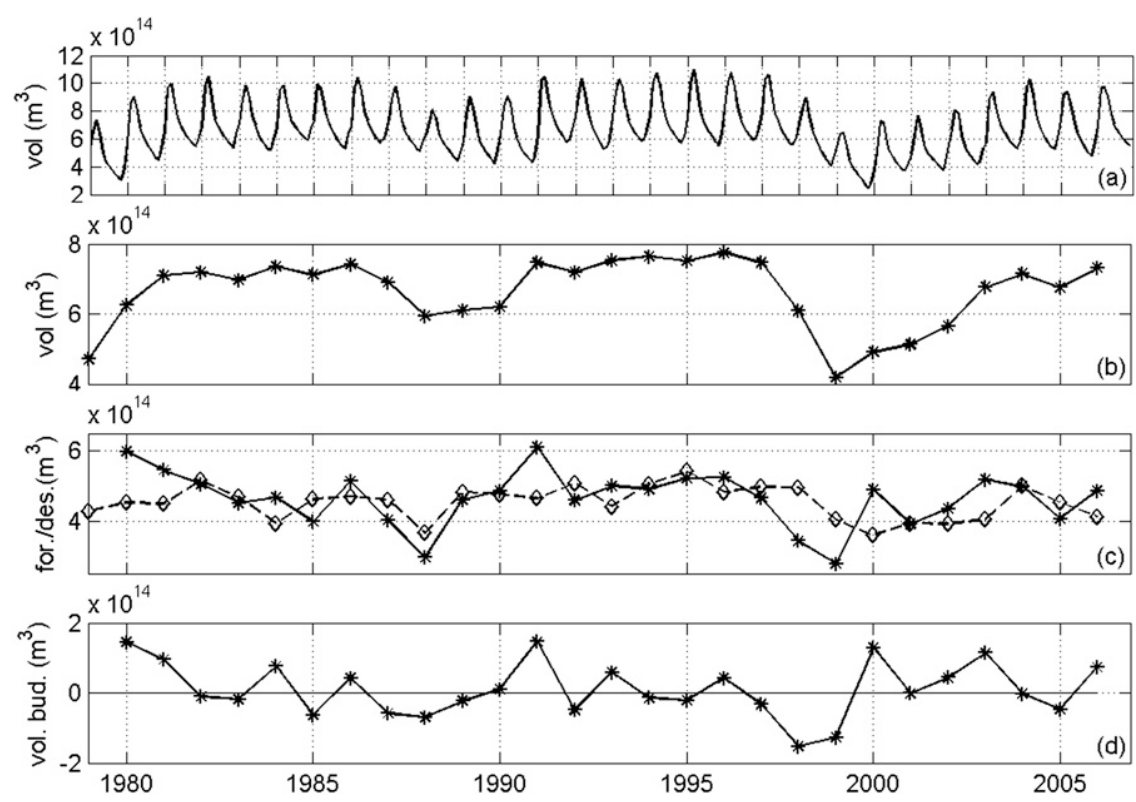

FIG. 9. (a) Monthly and (b) yearly averaged NPSTMW volume time series from the ECCO2 simulation. (c) The NPSTMW annual formation and destruction, solid and dashed lines, respectively. (d) The annual volume budget.

\section{b. Outcropping, the formation area of NPSTMW, local heat loss, and the mixed layer}

Intense buoyancy loss at the surface in the NPSTMW formation area is one of the most important mechanisms for NPSTMW formation (McCartney 1982). In the current work, the NPSTMW formation area (FA) is defined as the surface region where the isopycnals surrounds the NPSTMW outcrop and PV $\leq 2 \times 10^{-10} \mathrm{~m}^{-1} \mathrm{~s}^{-1}$. During winter months, strong convection around the KE region leads to restratification and therefore a lower PV in the upper ocean. The outcropping area almost coincides with the FA (dotted and solid lines in Fig. 10a), suggesting low PV water is found over nearly the entire outcropping region during winter months. The integrated heat loss from the ocean to the atmosphere (solid line in Fig. 10b) over the FA represents the direct heat loss in the NPSTMW FA, and this happens during the formation season, that is, from November to March. This direct heat loss integrated over the FA averaged from November to March for each year shows clear interannual variability, which correlates well with both the NPSTMW formation (Fig. 10b, dashed line) and the FA (Fig. 10a, solid line); the correlations are 0.76 and 0.74 , respectively, both significant at the $95 \%$ level of confidence. There is also a significant correlation (0.64) between NPSTMW formation and the FA. That is, during a year when there is larger (smaller) FA, heat loss is more (less), and more (less) NPSTMW forms.
NPSTMW is also associated with winter convection and the deep winter mixed layer. Previous studies have noted that low PV waters such as NPSTMW form at the point between the outcropping line and a so-called mixed layer depth (MLD) front where the MLD increases rapidly from values typical of an interior subtropical gyre (less than $100 \mathrm{~m}$ ) to more than $200 \mathrm{~m}$ near the Kuroshio-Oyashio region (KOE; Kubokawa 1999; Xie et al. 2000; Hosoda et al. 2004). To investigate the importance of the MLD index the MLD200 area (where MLD $\geq 200 \mathrm{~m}$ ) is calculated during the formation season (dashed line in Fig. 10a). The interannual changes of MLD200 are also found to be significantly correlated with the integrated heat loss over the FA with a correlation coefficient of 0.71 .

\section{c. Interannual variability of the volume-averaged properties of NPSTMW}

NPSTMW shows clear interannual variability in water properties such as temperature, salinity, PV, thickness, and average depth (Fig. 11). Closely tied to its volume, NPSTMW thickness exhibits a similar interannual trend (Figs. 11d and 9b), suggesting that the horizontal extent of NPSTMW does not vary significantly from year to year. Composed of newly formed NPSTMW and remaining NPSTMW from previous years, the interannual variability of other water properties is more complex and does not show a similar correlation with the NPSTMW volume time series. This quasi-decadal feature, however, 

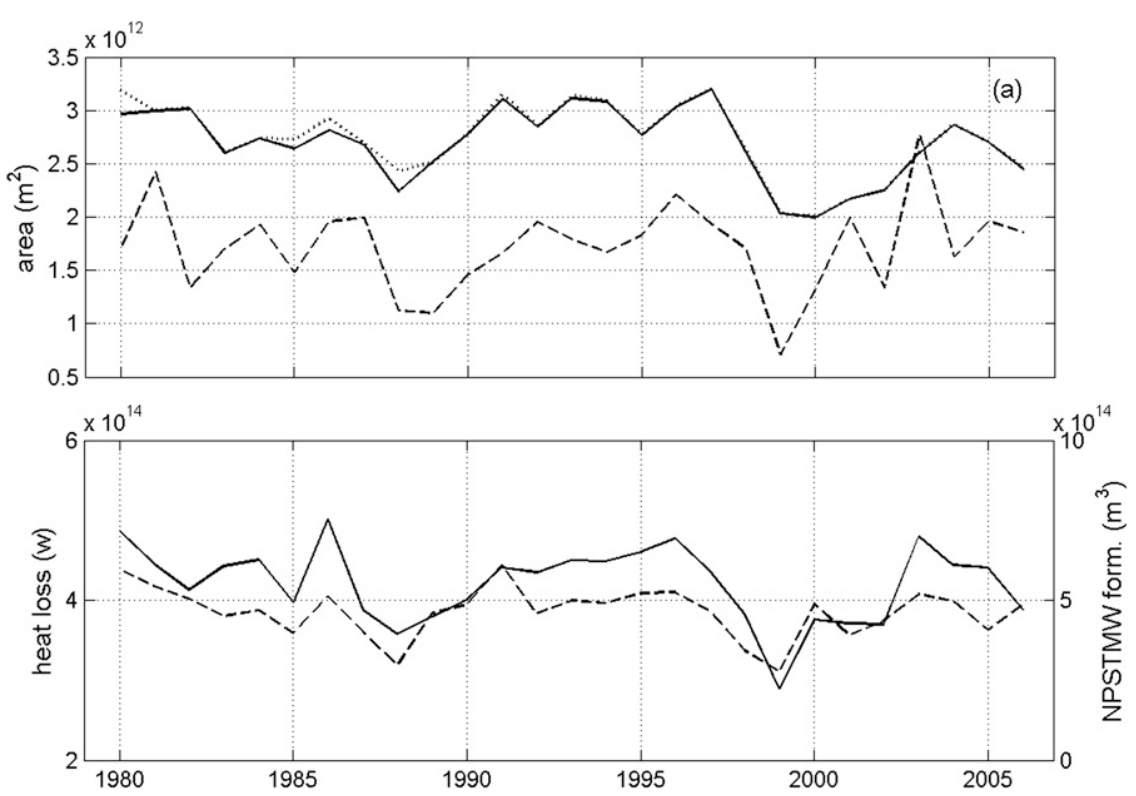

FIG. 10. (a) The outcropping area of NPSTMW (dotted line), the NPSTMW FA (solid line), and the area where the mixed layer depth is greater than $200 \mathrm{~m}$ (MLD200, dashed line); units of $\mathrm{m}^{2}$. (b) The integrated heat loss (W) over the NPSTMW FA (solid line; the $y$ axis is on the left) and the NPSTMW annual formation $\left(\mathrm{m}^{3}\right)$ (dashed line; the $y$ axis is on the right). The integrated net heat loss over FA here averaged over the formation season (from the previous November to the subsequent March).

can also been seen in NPSTMW temperature, salinity, and depth (Figs. 11a,b,e): NPSTMW is colder, fresher, and resides shallower around the end of each decade.

\section{NPSTMW interannual variability and its relation to Pacific climate variability}

One of the leading climate signals of the North Pacific, the PDO is monitored by an index, defined as the time component of the first EOF of SST north of $20^{\circ} \mathrm{N}$ in the Pacific Ocean (Fig. 12a). Based on this definition, and following the well known 1976/1977 North Pacific climate shift (Miller et al. 1994), the northeastern and tropical Pacific regions transitioned from a cool to warm phase (i.e., as measured by the warming of ocean surface temperatures), with a concomitant cooling in the centraleastern Pacific. This warm phase pattern dominated most of the period of present interest, with two phase changes from warm to cool around 1990 and 2000. As discussed earlier, the interannual variability of the NPSTMW volume exhibits quasi-decadal characteristics, with the volume minimum found toward the end of each decade. Thus, the two volume minimums coincide with the PDO phase shifts, from warm phase to cool phase, suggesting a relationship between the two. Indeed, we find a correlation coefficient of 0.59 between the NPSTMW volume and the PDO index, significant at the $95 \%$ confidence level. This correlation coefficient is also larger than Pearson's critical value (Sprinthall. 1990) thus supporting a significant relationship between NPSTMW volume and the PDO.

A recent observational study by Qiu and Chen (2006) supports these findings. Using satellite altimetry in conjunction with synoptic CTD and profiling float surveys during KESS, they report a representation of NPSTMW based on the thickness of the $16^{\circ}-18^{\circ} \mathrm{C}$ thermostad layer in the recirculation region and show that NPSTMW interannual variability follows a similar scenario as presented here: a gradual thinning in the $16^{\circ}-$ $18^{\circ} \mathrm{C}$ thermostad layer from 1993 to 1999 and a subsequent steady thickening of these features after 2000. The NPSTMW volume decrease from 1998 to 1999 is also seen in the POP simulation of Rainville et al. (2007). Instead of volume increasing from 1999 to 2000, however, the volume continues to decrease. Rainville et al. (2007) assert that the continuous volume decrease in POP during their 3 years of study is not solely due to model drift. The different trend of NPSTMW volume from 1999 to 2000 between the POP simulation and other studies may also be explained by differences in the NPSTMW definition and in model configuration.

The results presented here are in broad agreement with observations and enhance previous works through greater resolution, more complete spatial coverage, and 

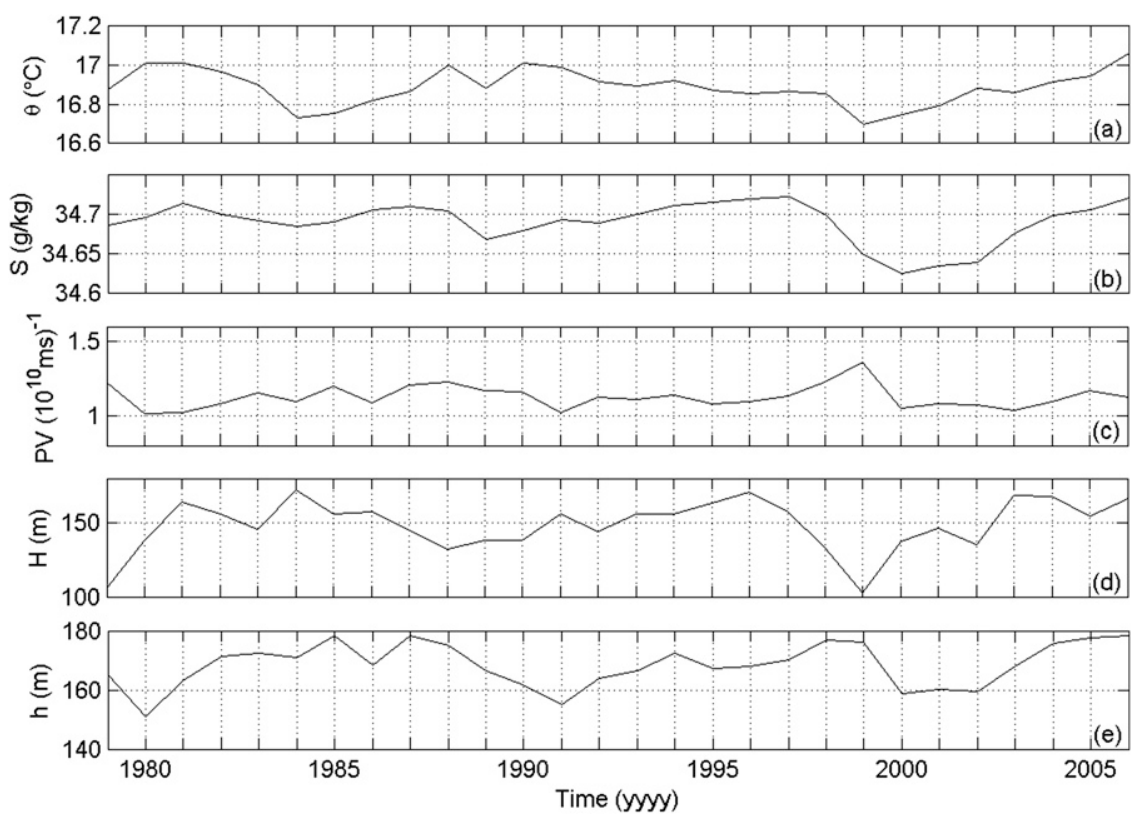

FIG. 11. The three-dimensional-averaged features of NPSTMW from year 1979 to 2006: (a) potential temperature $\theta\left({ }^{\circ} \mathrm{C}\right)$, (b) salinity $S\left(\mathrm{~g} \mathrm{~kg}^{-1}\right)$, (c) PV $\left(\times 10^{-10} \mathrm{~m}^{-1} \mathrm{~s}^{-1}\right)$, (d) thickness $H(\mathrm{~m})$, and (e) depth $h(\mathrm{~m})$.

longer time records. Furthermore, while the KOE region, the CLT of the NPSTMW, and North Pacific Central Mode Water have previously been found to be closely tied to Pacific climate signals (Deser et al. 1999; Schneider and Miller 2001; Ladd and Thompson 2002; Yasuda and Kitamura 2003; Taguchi et al. 2005), this is the first time that the STMW volume variability is examined in relation to the PDO. Comparing the lags between KOE and the PDO, the zero lag correlation between NPSTMW and PDO may have important implications for upper-ocean dynamics and will be investigated next.

\section{NPSTMW variability and atmosphere forcing}

The above correlation between NPSTMW volume and the PDO links NPSTMW to North Pacific decadal variations. Here, the dynamics and thermodynamics of NPSTMW variability, particularly on interannual scales, are sought by examining wind stress and surface heat

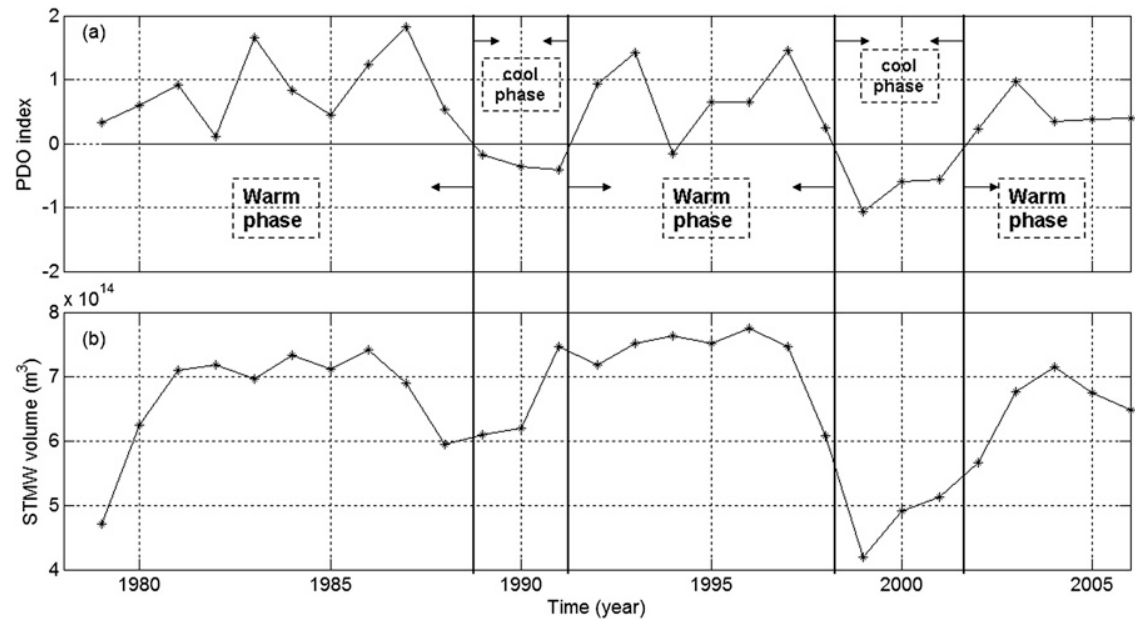

FIG. 12. (a) The PDO index and (b) NPSTMW volume from the ECCO2 simulation. In (a), the warm phases and cool phases stand for the different phases of PDO. 

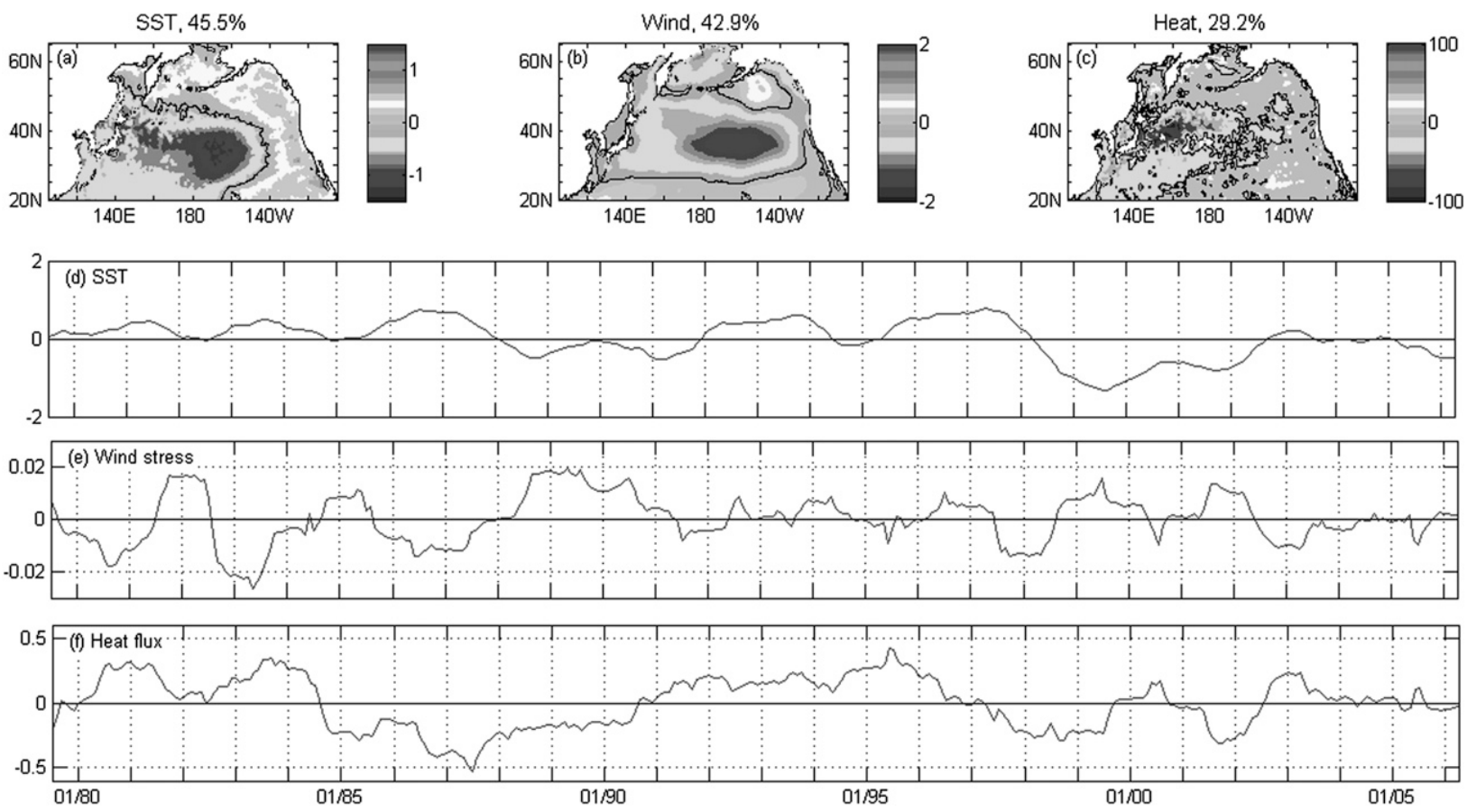

FIG. 13. Spatial distributions and time coefficients of the first EOF mode for (a),(d) SST $\left({ }^{\circ} \mathrm{C}\right)$; (b), (e) ERA-40 National Centers for Environmental Prediction (NCEP) wind stress magnitude $\left(\times 10^{-3} \mathrm{~N} \mathrm{~m}^{-2}\right)$; and (c),(f) net heat flux (W m $\left.{ }^{-2}\right)$ from atmosphere to ocean, with the ocean gaining heat when $Q_{\text {net }}>0$.

flux. We carried out an empirical orthogonal function (EOF) analysis of the wind stress and of surface heat flux to better understand the relationship between NPSTMW variability, the PDO index (with SST as its proxy), and atmospheric forcing. The wind stress and heat fluxes used to force the ECCO2 simulation are calculated from the ERA-40 and ECMWF atmospheric surface boundary conditions using bulk formulae. The net heat flux is $Q_{\text {net }}=Q_{\text {latent }}+Q_{\text {sensible }}+Q_{\text {shortwave }}+Q_{\text {longwave }}$, with the ocean gaining heat when $Q_{\text {net }}>0$. Monthly time series anomalies are low-pass filtered using a 13-point Hanning filter to filter the seasonal signal. Subsequently, the first four EOFs of the filtered signal are calculated. The time coefficient of the first EOF for SST exhibits decadal-scale variations (Figs. 13a,d), with the largest negative SST anomaly in the central-eastern Pacific $\left(30^{\circ} \mathrm{N}, 170^{\circ} \mathrm{W}\right)$. This negative anomaly weakens toward the southwest, with the eastern and northern parts of the North Pacific populated with positive anomalies. This first EOF captured as much as $45.5 \%$ of the total variance. Inspection of the time coefficient of the first EOF for SST (PDO index) shows a change of sign around 1990 and 2000 as the northeastern Pacific switches from a warm to cool phase. The time coefficients of the first EOF of wind and heat flux are coherent with decadal fluctuations as well (Figs. 13e,f). For example, the NPSTMW volume minimum corresponds with this cool phase during which the SST gets warmer (Figs. 13a,d), the wind gets weaker (Figs. 13b,e), and the ocean loses less heat to the atmosphere (Figs. 13c,f) in the subtropical gyre region. Further examination of the first EOF of the atmospheric forcing show that the wind stress magnitude correlates with the PDO index, with basin-scale wind leading the PDO index (SST) by 3 months with a lag correlation coefficient of -0.51 (Fig. 14). The basin-scale air-sea heat exchange is also correlated with the PDO index but with a smaller correlation of $\sim 0.35$ and a double-peak structure. In addition, there is a correlation coefficient of 0.48 between the first EOF component of the wind stress and the net heat flux with zero time lag (not shown).

The analysis above identifies distinct correlations between low-frequency NPSTMW volume and variability in the basin-sale atmospheric forcing. We can, however, learn more about how these mechanisms might play a role in interannual NPSTMW variability through an examination of specific cases in the record. Two cases are of particular interest: the period when the NPSTMW volume was maximum (1996) and the period when it was minimum (1999). Each of these events may be analyzed from the point of view of the heat flux variability as well as from the perspective of variations in the overlying atmospheric wind stress patterns. As will be shown, each perspective provides 


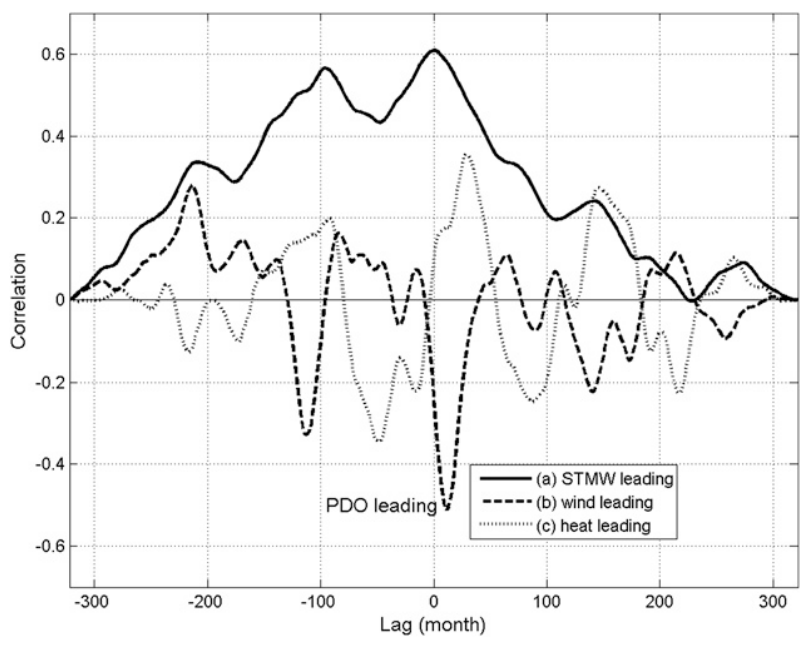

FIG. 14. Lag correlation between the low-pass-filtered monthly PDO index and NPSTMW volume (solid line), the time coefficient of the first EOF of wind magnitude (dashed line), and the time coefficient of the first EOF of net heat flux (dotted line).

credible justification for the resulting variation in model NPSTMW volume. It is more likely, however, that they both have a role to play in causing the observed fluctuations. For each of these two case studies, we examine the formation period prior to the observed NPSTMW volume extrema. Simulation results from November to February are taken as representative of the NPSTMW formation period.
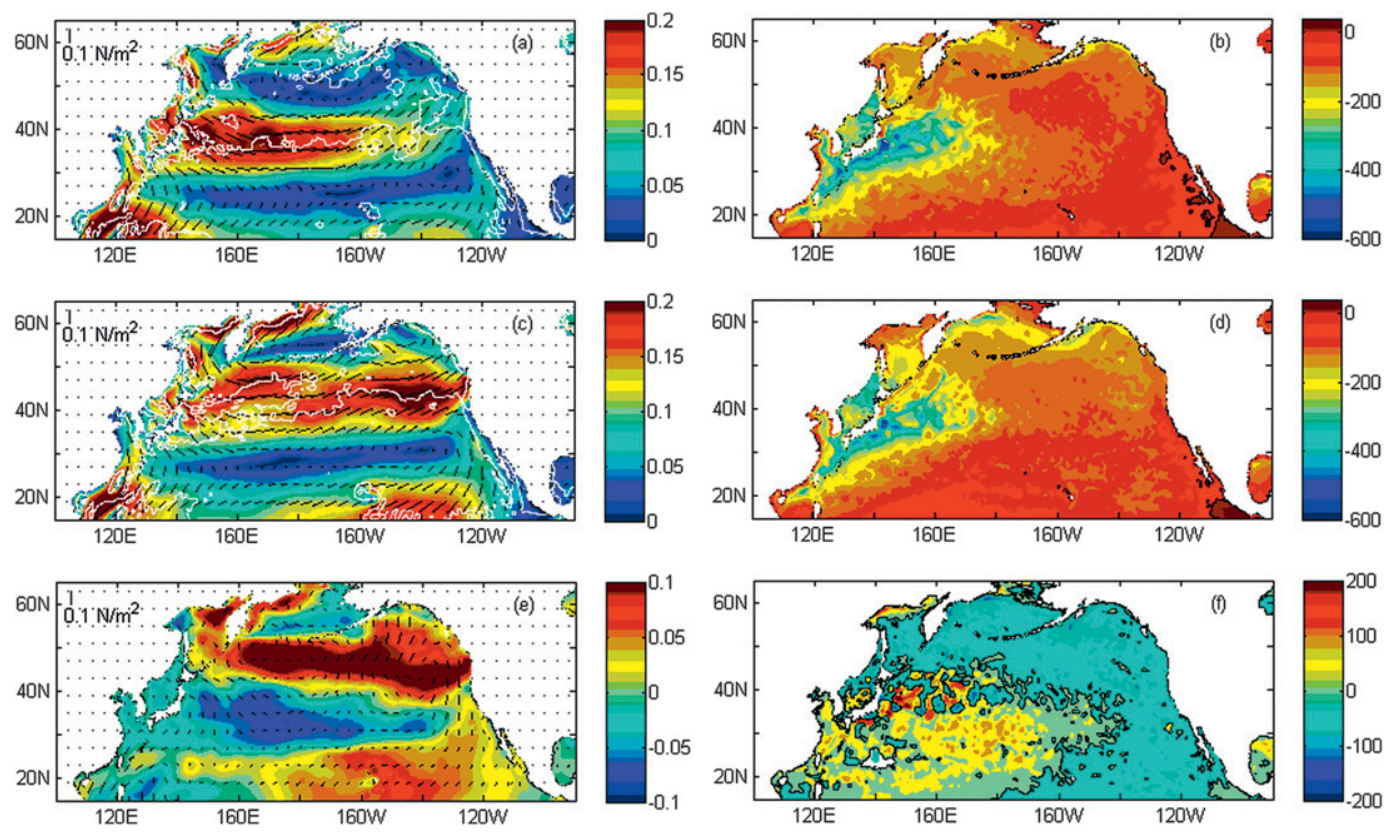

FIG. 15. Wind stress magnitude (colors) and wind stress vectors (black arrows) in winter (Nov-Feb) for (a) 1995/1996, (c) 1998/1999, and (e) the difference between (a) and (c), where the white line is a zero wind stress curl. (b)-(f) As in (a)-(e), but for the net heat flux; here the black line denotes the zero heat flux difference. 
warming of the near-surface layers, thereby generating a more stratified upper ocean, shallower mixed layer, and less local heat loss. This may inhibit the necessary wintertime convection essential for new NPSTMW formation. Previous studies have further argued that a second mechanism, heat divergence within the Ekman layer in the northern subtropical gyre, may also result in upperocean heating (Deser and Blackmon 1995; Yasuda and Hanawa 1997).

\section{b. Net heat flux}

Analysis of the ECCO2 simulation also shows significant correlation between surface heat flux, the wind stress, and NPSTMW volume and deserves further attention. In the NPSTMW extrema cases, the heat flux (Figs. 15b,d,f) appears to precondition the upper ocean in terms of NPSTMW, that is, variations in the surface heat flux drive changes in the SST. This is particularly pronounced in the subtropical gyre during winter and is most evident near the Kuroshio and KE, one of the most prominent regions of air-sea heat exchange. Indeed, significant ocean heat loss to the atmosphere can be seen in the winter months (Figs. 15b,d) of each case.

In the comparison of the formation region and surrounding waters of the northwest subtropical gyre during the 1995/1996 volume maximum and the 1998/1999 minimum, different heat loss regimes are apparent. In both cases, the NPSTMW formation region is characterized by significant heat loss to the atmosphere (Figs. $15 \mathrm{~b}, \mathrm{~d})$. Differencing the heat flux between the two cases shows that greater heat loss occurs during the winter of 1995/1996 (Fig. 15f). A comparison of SST between these two cases further substantiates this finding (not shown). The differences in these heat loss regimes cover the majority of the defined NPSTMW region $\left(20^{\circ}-40^{\circ} \mathrm{N}\right.$, $\left.130^{\circ} \mathrm{E}-160^{\circ} \mathrm{W}\right)$. This further supports the earlier finding that the NPSTMW volume variability is correlated with the integrated heat loss over FA.

\section{Conclusions and discussion}

A high-resolution ECCO2 simulation was used to study the seasonal phases of NPSTMW. This then forms the foundation for better understanding the role of NPSTMW in lower-frequency Pacific climate variability. During a 335-month model time period (from January 1979 to November 2006), the seasonal variability is, not surprisingly, the dominant temporal variation observed. The monthly mean seasonal cycle of NPSTMW in the simulation exhibits three distinct phases: formation, isolation, and dissipation. An interannual signal is also evident in NPSTMW volume and other characteristic properties, with this signal directly determined by the yearly differences in NPSTMW formation and destruction. The interannual formation of NPSTMW is found to be significantly correlated with the integrated heat loss over the FA during the formation season. Both the outcropping and the MLD200 area changes are also correlated with this integrated heat loss and therefore with NPSTMW formation. That is, when there is more surface cooling the outcropping area of NPSTMW is larger and more NPSTMW forms.

A distinct interannual signal of NPSTMW in the ECCO2 simulation also emerged and is found to be correlated with a well-established climate index of the North Pacific Ocean. The correlation between NPSTMW volume variability and the PDO index suggests that lowerfrequency NPSTMW variability is linked to large-scale variations in the regional atmosphere. The NPSTMW volume minimum is found when the PDO changes from its warm phase to a cool phase around the end of each decade. This supports a hypothesis that the mechanism connecting NPSTMW and decadal variability patterns is tied to basin-scale atmospheric forcing.

This hypothesis is investigated with an EOF analysis of the wind stress and net air-sea heat flux used to force the GCM. Results show significant correlation between NPSTMW volume and the first EOF of the wind stress. Basin-scale heat flux, in contrast to the significant correlation between the local heat loss and NPSTMW volume variability, does not correlate highly with the NPSTMW volume variation. It is plausible that the basin-scale wind stress impacts on the local heat flux, then influences the local NPSTMW formation. Specifically, more (less) NPSTMW is observed during the time when the wind stress is strong (weak) and more (less) heat loss occurs from the ocean to the atmosphere around the NPSTMW formation region. Essentially, NPSTMW volume appears directly connected to the basin-scale atmospheric forcings, that is, the wind stress influencing the heat flux.

To establish physical causality (i.e., linear dependence) for these correlations, we investigate some specific cases. It is found that NPSTMW volume varies with the position and intensity of the prevailing westerlies of the region: the northward shift of the westerlies corresponds with periods of NPSTMW volume decrease and, conversely, a more southerly position of the westerlies coincides with NPSTMW volume increase. Explanations for this are that 1) the northward (southward) shift of the westerlies produces a weaker (stronger) wind stress over the NPSTMW formation region, resulting in less (more) heat loss to the atmosphere and less (more) NPSTMW, and 2) weaker westerlies in the NPSTMW formation area lead to less Ekman transport of the cold water from the north and the resulting warmer subsurface ocean 

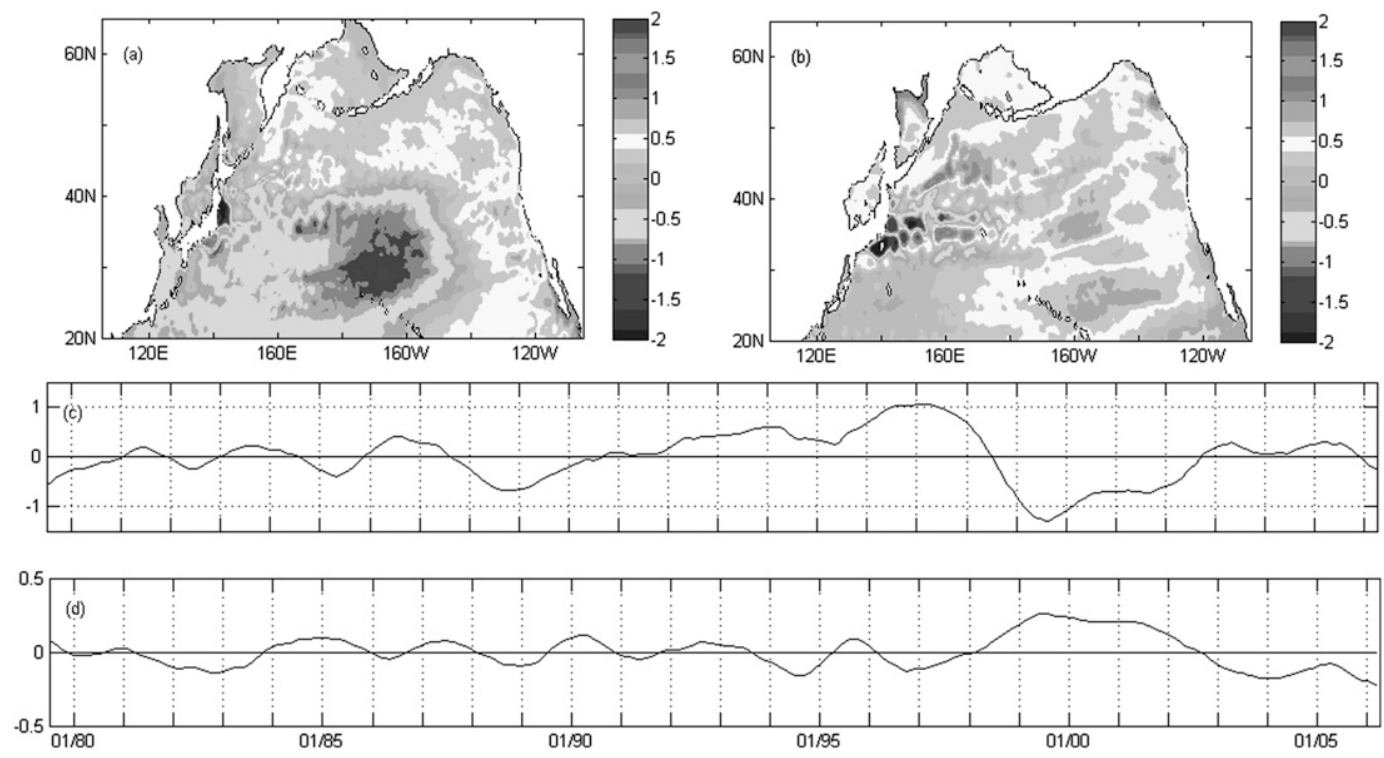

FIG. 16. The EOF analysis of the ECCO2 temperature fields at different depths. Spatial distribution of the first EOF for (a) 50 and (b) $400 \mathrm{~m}$. The time coefficients for (c) 50 and (d) $400 \mathrm{~m}$.

impedes wintertime convection and NPSTMW formation. Both of these impacts directly affect winter mixed layers in the NPSTMW formation region. Kelly and Dong (2004) suggest that the strength of the westerlies is the source of the ocean advection, which in turn causes most of the interannual changes in heat content. Similar anticorrelations between heat content and NPSTMW formation have also been studied in related works (Kelly and Dong 2004; Kwon 2003; Yasuda and Hanawa 1997). The case study of the heat flux further supports the important role of the local heat flux in NPSTMW volume variability. The heat flux largely controls the strong seasonality observed in the model NPSTMW and also plays an important role in interannual variability of NPSTMW. Focusing on the NPSTMW in the recirculation gyre (RG), Qiu and Chen (2006) reported that little correlation is found instead between the NPSTMW variability and the year-to-year changes in the cumulative wintertime surface cooling from year 1993 to 2004. To investigate this difference, we calculated NPSTMW volume and the integrated wintertime heat loss averaged over the RG as defined by Qiu and Chen (2006). In agreement with their result, the NPSTMW volume and the above-mentioned heat flux do not correlate with each other significantly in RG alone. This supports that the NPSTMW in the RG exhibits different dynamics from the rest of the NPSTMW because of its vicinity to Kuroshio and KE.

Previous studies have addressed the relationship between the basin-scale wind pattern and KOE variability. Specifically, the role of the first baroclinic Rossby wave has been shown to be important; the Rossby wave is the primary messenger of wind variability from the central Pacific to the KOE region over a time scale of 3-5 years (Deser et al. 1999; Yasuda and Kitamura 2003), impacting thermocline variability (Hosoda et al. 2004), KE transport (Hanawa and Kamada 2001), and the subtropical front (Yamanaka et al. 2008) in the NPSTMW formation region. The result presented here shows that there is a zero lag correlation instead between STMW volume variability, PDO index, and basin-scale wind stress pattern. This time difference suggests that different mechanisms account for NPSTMW formation and subsurface variability in the KOE region.

NPSTMW formation is directly linked to winter convection and mixed layer dynamics; the winter mixed layer depth distribution is critical to mode water formation (Xie et al. 2000). The thermal variability within the winter mixed layer is mainly a result of heat flux anomalies at the sea surface caused by changes in atmospheric circulation with a relatively rapid response time of less than one year (Alexander 1992; Luksch and von Storch 1992; Miller et al. 1994; Deser et al. 1999). The subsurface variability, usually represented by temperature at $400 \mathrm{~m}$, is isolated from surface contact and principally influenced by Sverdrup dynamics and with a time lag corresponding to the propagation speed of the first baroclinic Rossby wave. The EOF analysis of the temperature at different depths supports this argument (Fig. 16). At $50 \mathrm{~m}$ (Figs. 16a,c), representative of mixed layer variability, the thermal structure exhibits a basinscale distribution, similar to that of SST and wind stress 
(Fig. 13). At $400 \mathrm{~m}$, a proxy for the subsurface/thermocline, the largest variance is concentrated around the KOE region. The 1998 phase shift occurring at $50 \mathrm{~m}$ (Fig. 16c) did not happen until 2002 at 400 m (Fig. 16d). Clearly there is a $\sim 4$-yr lag between the mixed layer variability and thermocline variations. Similar results were also found in Deser et al. (1999) using the World Ocean Atlas 1994 (WOA94).

The results presented here are also supported by studies of the subduction rate in the North Pacific. Subduction rate, or the volume flux of mixed layer water entering the thermocline per unit horizontal area, is the key to the low PV mode water mass formation (CushmanRoisin 1987; Williams 1991; Qu et al. 2002; Tsujino and Yasuda 2004). Among others, Qu et al. (2002) show that the annual subduction rate, dominated by lateral induction (mixed layer change), has its maximum in the NPSTMW and central mode water formation region in the North Pacific. Therefore, the interannual variability of North Pacific subduction is directly linked to the NPSTMW formation and volume on interannual scales. More recently in Qu and Chen (2009), a zero lag correlation between the North Pacific subduction rate and the PDO index has been identified consistent with our findings. It is also reported that this correlation is caused by the surface wind and heat flux influencing the winter mixed layer (Qu and Chen 2009; Chen et al. 2010). Additionally, the role of the surface heat flux and large-scale wind stress patterns on the formation of North Pacific mode waters in a warmer climate has also been studied (Luo et al. 2009); less mode water is formed owing to a more stratified ocean. This result is in agreement with the cool phase of the PDO studied here, when the NPSTMW formation region has a weaker wind, less heat loss, a warmer upper ocean, and less NPSTMW formation.

Although formed locally, NPSTMW is tied to the basin-scale circulation and an essential component of the basin-wide subtropical gyre circulation system. A theoretical framework (Dewar et al. 2005) also supports this finding. Based on this work, the dynamical impact of the large-scale wind and surface heat forcing on the NPSTMW has been further examined using a planetary geostrophic ocean model (X. J. Davis et al. 2010, unpublished manuscript), which resembles the analytical solution of the theoretical framework by Dewar et al. (2005). Additionally, mesoscale eddies are highly active in the KOE region and influence the formation and transportation of NPSTMW (Uehara et al. 2003). The NPSTMW residing within eddies such as the anticyclonic eddies discussed by Uehara et al. (2003) may carry its unique characteristics compared to the integrated features of NPSTMW presented in this study, in which the ECCO2 simulation used is eddy permitting but not eddy resolving. This aspect is also important and is the subject of ongoing studies.

Acknowledgments. We would like to express our sincere appreciation to the two anonymous reviewers for their valuable comments. We would also like to thank Young-Oh Kwon, Ruixin Huang, Tangdong Qu, and Shannon Davis for insightful discussions. Support for this research was provided by the Partnership for Advancing Interdisciplinary Modeling (PARADIGM), a National Ocean Partnership Program and by a NASA Modeling, Analysis, and the Prediction (MAP) project called Estimating the Circulation and Climate of the Ocean, Phase II (ECCO2). Part of this research was carried out at the Jet Propulsion Laboratory, California Institute of Technology, under a contract with the National Aeronautics and Space Administration.

\section{REFERENCES}

Adcroft, A. J., J.-M. Campin, C. N. Hill, and J. Marshall, 2004: Implementation of an atmosphere-ocean general circulation model on the expanded spherical cube. Mon. Wea. Rev., 132, 2845-2863.

Adler, R. F., and Coauthors, 2003: The version 2 Global Precipitation Climatology Project (GPCP) monthly precipitation analysis (1979-Present). J. Hydrometeor., 4, 1147-1167.

Alexander, M., 1992: Midlatitude atmosphere-ocean interaction during El Niño. Part I: The North Pacific Ocean. J. Climate, 5, 944-958.

Bingham, F. M., 1992: The formation and spreading of subtropical mode water in the North Pacific. J. Geophys. Res., 97, 11 17711189.

Chen, J., T. Qu, Y. Sasaki, and N. Schneider, 2010: Anti-correlated variability in subduction rate of the western and eastern North Pacific Oceans. J. Geophys. Res. Lett., 37, L23608, doi:10.1029/ 2010GL045239.

Cushman-Roisin, B., 1987: Dynamics of the oceanic surface mixed layer. Hawaii Institute of Geophysics Special Publications, P. Muller and D. Henderson, Eds., Hawaii Institute of Geophysics, 181-196.

Deser, C., and M. L. Blackmon, 1995: On the relationship between tropical and North Pacific sea surface temperature variations. J. Climate, 8, 1677-1680.

— M. A. Alexander, and M. S. Timlin, 1999: Evidence for a wind-driven intensification of the Kuroshio Current extension from the 1970s to the 1980s. J. Climate, 12, 1697-1706.

Dewar, W. K., R. M. Samelson, and G. K. Vallis, 2005: The ventilated pool: A model of subtropical mode water. J. Phys. Oceanogr., 35, 137-150.

Fox-Kemper, B., and D. Menemenlis, 2008: Can large eddy simulation techniques improve mesoscale rich ocean models? Ocean Modeling in an Eddying Regime, Geophys. Monogr., Vol. 177, Amer. Geophys. Union, 319-388.

Gibson, J. K., P. Kållberg, S. Uppala, A. Hernandez, A. Nomura, and E. Serrano, 1997: ERA description. ERA Project Rep. Series 1, ECMWF, 18 pp.

Hanawa, K., and J. Kamada, 2001: Variability of core layer temperature (CLT) of the North Pacific Subtropical Mode Water. Geophys. Res. Lett., 28, 2229-2232. 
Hosoda, S., S.-P. Xie, K. Takeuchi, and M. Nonaka, 2004: Interdecadal temperature variations in the North Pacific Central Mode Water simulated by an OGCM. J. Oceanogr., 60, 865-877.

Jenkins, W. J., 1982: On the climate of a subtropical ocean gyre: Decadal time scale variations in water mass renewal in the Sargasso Sea. J. Mar. Res., 40 (Suppl.), 265-290.

Kelly, K. A., and S. Dong, 2004: The relationship of western boundary current heat transport and storage to mid-latitude ocean-atmosphere interaction. Earth's Climate: The OceanAtmosphere Interaction, Geophys. Monogr., Vol. 147, Amer. Geophys. Union, 347-363.

Kubokawa, A., 1999: Ventilated thermocline strongly affected by a deep mixed layer: A theory for subtropical countercurrent. J. Phys. Oceanogr., 29, 1314-1333.

Kwon, Y.-O., 2003: Observation of general circulation and water mass variability in the North Atlantic Subtropical Mode Water region. Ph.D. thesis, University of Washington, $161 \mathrm{pp}$.

_- and S. C. Riser, 2004: North Atlantic Subtropical Mode Water: A history of ocean-atmosphere interaction 1961-2000. Geophys. Res. Lett., 31, L19307, doi:10.1029/2004GL021116.

Ladd, C., and L. Thompson, 2001: Water mass formation in an isopycnal model of the North Pacific. J. Phys. Oceanogr., 31, $1517-1537$.

— , and — 2002: Decadal variability of North Pacific Central Mode Water. J. Phys. Oceanogr., 32, 2870-2881.

Large, W. G., and S. Pond, 1982: Sensible and latent heat flux measurement over the ocean. J. Phys. Oceanogr., 12, 464-482.

— J. C. McWilliams, and S. Doney, 1994: Oceanic vertical mixing: A review and a model with a nonlocal boundary layer parameterization. Rev. Geophys., 32, 363.

_ - J. Morzel, and G. Crawford, 1995: Accounting for surface wave distortion of the marine wind profile in low-level ocean storms wind measurements. J. Phys. Oceanogr., 25, 29592971.

Latif, M., and T. P. Barnett, 1994: Causes of decadal climate variability over the North Pacific and North America. Science, 266, 634-637.

Luksch, U., and H. von Storch, 1992: Modeling the low-frequency sea surface temperature variability in the North Pacific. J. Climate, 5, 893-906.

Luo, Y., Q. Liu, and L. M. Rothstein, 2009: Simulated response of North Pacific Mode Waters to global warming. Geophys. Res. Lett., 36, L23609, doi:10.1029/2009GL040906.

Marshall, J., A. Adcroft, C. Hill, L. Perelman, and C. Heisey, 1997: A finite-volume, incompressible Navier-Stokes model for studies of the ocean on parallel computers. J. Geophys. Res., 102, 5753.

Masuzawa, J., 1969: Subtropical mode water. Deep-Sea Res., 16, 463-472.

McCartney, M., 1982: The subtropical recirculation of mode waters. J. Mar. Res., 40 (Suppl.), 427-464.

Menemenlis, D., I. Fukumori, and T. Lee, 2005a: Using Green's functions to calibrate an ocean general circulation model. Mon. Wea. Rev., 133, 1224-1240.

- , and Coauthors, 2005b: NASA supercomputer improves prospects for ocean climate research. Eos, Trans. Amer. Geophys. Union, 86, 89, doi:10.1029/2005EO090002.

— , P. Heimbach, C. Hill, T. Lee, A. Nguyen, M. Schodlok, and H. Zhang, 2008: ECCO2: High-resolution global ocean and sea ice data synthesis. Mercator Ocean Quarterly Newsletter, Vol. 31, Mercator Ocean, Agne, France, 13-21.
Miller, A. J., D. R. Cayan, T. P. Barnett, N. E. Graham, and J. M. Oberhuber, 1994: Interdecadal variability of the Pacific Ocean: Model response to observed heat flux and wind stress anomalies. Climate Dyn., 9, 287-302.

Oka, E., 2009: Seasonal and Interannual Variation of North Pacific Subtropical Mode Water in 2003-06. J. Oceanogr., 65, 151-164.

— , and T. Suga, 2003: Formation region of North Pacific Subtropical Mode Water in the late winter of 2003. Geophys. Res. Lett., 30, 2205, doi:10.1029/2003GL018581.

Qiu, B., and S. Chen, 2006: Decadal variability in the formation of the North Pacific Subtropical Mode Water: Oceanic versus atmospheric control. J. Phys. Oceanogr., 36, 1365-1380.

_ P. Hacker, S. Chen, K. A. Donohue, D. R. Watts, H. Mitsudera, N. G. Hogg, and S. R. Jayne, 2006: Observations of the subtropical mode water evolution from the Kuroshio Extension system study. J. Phys. Oceanogr., 36, 457-473.

- S. Chen, and P. Hacker, 2007: Effect of mesoscale eddies on subtropical mode water variability from the Kuroshio Extension System Study (KESS). J. Phys. Oceanogr., 37, 982-1000.

Qu, T., and J. Chen, 2009: A North Pacific decadal variability in subduction rate. Geophys. Res. Lett., 36, L22602, doi:10.1029/ 2009GL040914.

— S.-P. Xie, H. Mitsudera, and A. Ishida, 2002: Subduction of the North Pacific Mode Waters in a global high-resolution GCM. J. Phys. Oceanogr., 32, 746-763.

Rainville, L., S. R. Jayne, J. L. McClean, and M. E. Maltrud, 2007: Formation of subtropical mode water in a high-resolution ocean simulation of the Kuroshio Extension region. Ocean Modell., 17, 338-356.

Roemmich, D., J. Gilson, J. Willis, P. Sutton, and K. Ridgway, 2005: Closing the time-varying mass and heat budgets for large ocean areas: The Tasman box. J. Climate, 18, 2330-2343.

Schneider, N., and A. Miller, 2001: Predicting western North Pacific Ocean climate. J. Climate, 14, 3997-4002.

Speer, K., and E. Tziperman, 1990: Convection from a source in an ocean basin. Deep-Sea Res., 37, 431-446.

Sprinthall, R. C., 1990: Basic Statistical Analysis. 3rd ed. Prentice Hall, 468 pp.

Suga, T., and K. Hanawa, 1990: The mixed-layer climatology in the northwestern part of the North Pacific subtropical gyre and the formation area of the subtropical mode water. J. Mar. Res., 48, $543-566$.

— , and - 1995: The subtropical mode water circulation in the North Pacific. J. Phys. Oceanogr., 25, 958-970.

Taguchi, B., S.-P. Xie, H. Mitsudera, and A. Kubokawa, 2005: Response of the Kuroshio Extension to Rossby waves associated with the 1970 s climate regime shift in a high-resolution ocean model. J. Climate, 18, 2979-2995.

Taneda, T., T. Suga, and K. Hanawa, 2000: Subtropical mode water variation in the northwestern part of the North Pacific subtropical gyre. J. Geophys. Res., 105, 19 591-19 598.

Tsujino, H., and T. Yasuda, 2004: Formation and circulation of the mode waters of the North Pacific in a high-resolution GCM. J. Phys. Oceanogr., 34, 399-415.

Uehara, H., T. Suga, K. Hanawa, and N. Shikama, 2003: A role of eddies in formation and transport of North Pacific Subtropical mode water. Geophys. Res. Lett., 30, 1705, doi:10.1029/ 2003 GL017542.

Uppala, S. M., and Coauthors, 2005: The ERA-40 Re-Analysis. Quart. J. Roy. Meteor. Soc., 131, 2961-3012.

Williams, R. G., 1991: The Role of the mixed layer in setting the potential vorticity of the main thermocline. J. Phys. Oceanogr., 21, 1803-1814. 
Worthington, L. V., 1959: The $18^{\circ}$ water in the Sargasso Sea. DeepSea Res., 5, 297-305.

Xie, S.-P., T. Kunitani, A. Kubokawa, M. Nonaka, and S. Hosoda, 2000: Interdecadal thermocline variability in the North Pacific for 1958-1997: A GCM simulation. J. Phys. Oceanogr., 30, 2798-2813.

Yamanaka, G., H. Ishizaki, M. Hirabara, and I. Ishikawa, 2008: Decadal variability of the Subtropical Front of the western North
Pacific in an eddy-resolving ocean general circulation model. J. Geophys. Res., 113, C12027, doi:10.1029/2008JC005002.

Yasuda, T., and K. Hanawa, 1997: Decadal changes in the mode waters in the midlatitude North Pacific. J. Phys. Oceanogr., 27, 858-870.

, and Y. Kitamura, 2003: Long-term variability of the North Pacific subtropical mode water in response to the spin-up of the subtropical gyre. J. Oceanogr., 9, 279-290. 